\title{
In vitro evaluation of anticancer nanomedicines based on doxorubicin and amphiphilic Y-shaped copolymers
}

This article was published in the following Dove Press journal:

International Journal of Nanomedicine

30 May 2012

Number of times this article has been viewed

\author{
Di Li ${ }^{1,2, *}$ \\ Jian Xun Ding ${ }^{1,3, *}$ \\ Zhao Hui Tang' \\ Hai Sun' \\ Xiu Li Zhuang' \\ jing Zhe $X u^{2}$ \\ Xue Si Chen' \\ 'Key Laboratory of Polymer \\ Ecomaterials, Changchun Institute \\ of Applied Chemistry, Chinese \\ Academy of Sciences, Changchun, \\ ${ }^{2}$ Department of Chemistry, Yanbian \\ University, Yanji, ${ }^{3}$ Graduate University \\ of Chinese Academy of Sciences, \\ Beijing, China \\ *These authors contributed equally \\ to this work
}

\begin{abstract}
Four monomethoxy poly(ethylene glycol)-poly(L-lactide-co-glycolide) $)_{2}$ (mPEG$\mathrm{P}(\mathrm{LA}-\mathrm{Co}-\mathrm{GA})_{2}$ ) copolymers were synthesized by ring-opening polymerization of L-lactide and glycolide with double hydroxyl functionalized mPEG (mPEG- $\left.(\mathrm{OH})_{2}\right)$ as macroinitiator and stannous octoate as catalyst. The copolymers self-assembled into nanoscale micellar/vesicular aggregations in phosphate buffer at pH 7.4. Doxorubicin (DOX), an anthracycline anticancer drug, was loaded into the micellar/vesicular nanoparticles, yielding micellar/vesicular nanomedicines. The in vitro release behaviors could be adjusted by content of hydrophobic polyester and $\mathrm{pH}$ of the release medium. In vitro cell experiments showed that the intracellular DOX release could be adjusted by content of P(LA-co-GA), and the nanomedicines displayed effective proliferation inhibition against Henrietta Lacks's cells with different culture times. Hemolysis tests indicated that the copolymers were hemocompatible, and the presence of copolymers could reduce the hemolysis ratio of DOX significantly. These results suggested that the novel anticancer nanomedicines based on DOX and amphiphilic Y-shaped copolymers were attractive candidates as tumor tissular and intracellular targeting drug delivery systems in vivo, with enhanced stability during circulation and accelerated drug release at the target sites.
\end{abstract}

Keywords: amphiphilic Y-shaped copolymer, anticancer nanomedicine, cellular proliferation inhibition, doxorubicin

\section{Introduction}

Over the past decade, a new era in nanosized polymer-based pharmaceuticals has emerged, via interface of chemistry and biomedical science, to improve the efficacy of cancer chemotherapy. ${ }^{1,2}$ Amphiphilic copolymers have been widely studied as economic and versatile nanoscale drug carriers, due to their typical diameter of several tens of nanometers and relatively narrow size distribution..$^{3-5}$ The unique compositions, molecular geometry, and physicochemical properties of the amphiphilic copolymers enable them to aggregate into nanoparticles with various morphologies in aqueous medium, such as micelles ${ }^{6-9}$ and vesicles. ${ }^{10-12}$ The nanomedicines based on the abovementioned polymeric micellar/vesicular nanoparticles can effectively resist rapid renal clearance and nonspecific uptake by the reticuloendothelial system (RES). In addition, the nanoparticles can deliver anticancer drugs and genetic agents into target pathological sites, due to the enhanced permeability and retention (EPR) effect in tumor vasculature, which improve the efficacy of chemotherapy and reduce the side effects of the loaded drug to healthy tissues. ${ }^{4,13-16}$

Previous studies on micellar/vesicular nanovehicles for anticancer drug delivery have focused mainly on the synthesis and self-assembly of linear amphiphilic 
di/triblock copolymers. Traditional linear amphiphilic block copolymers have been able to self-assemble into stabile nanoparticles as drug carriers in aqueous solution. However, their low drug-loading efficiency and uncontrollable degradation have limited their usage in drug delivery. ${ }^{17}$ As such, more attention has been paid to amphiphilic miktoarm star-shaped copolymers with two or more types of chemically different arms, as they might completely or partially overcome the problem of thermodynamic instability associated with micelles assembled from linear amphiphilic di/triblock copolymers. ${ }^{13,18-20}$ Due to their particular molecular architecture, star-shaped copolymers are expected to exhibit different properties compared with their linear counterparts. For instance, amphiphilic starshaped copolymers are superior in host-guest interactions and drug delivery compared to conventional linear ones. ${ }^{21-25}$ Typically, several synthetic strategies, such as atom transfer or nitroxide-mediated radical polymerization (ATRP or NMP) ${ }^{26}$ reversible addition fragmentation chain transfer (RAFT), ring-opening polymerization (ROP), ${ }^{27}$ and "click chemistry" reactions, ${ }^{28}$ have been successfully employed in the preparation of star-shaped copolymers with welldefined macromolecular building blocks and architecture. However, the undegradability of the resultant polymer has restricted the development of the ATRP, NMP, and RAFT methods; the biodegradable blocks can be introduced through ROP. Aliphatic polyesters, such as poly( $\varepsilon$-caprolactone) (PCL), poly(L-lactide) (PLA), and poly(L-lactide-co-glycolide) (PLGA), ${ }^{29}$ are the most common hydrophobic moieties that act as bioactive molecule reservoirs, due to their excellent biocompatibility and biodegradability. For biomedical applications, however, the hydrophilic segments are composed of zwitterionic material or polyethylene glycol (PEG), which can resist nonspecific protein adsorption (ie, nonfouling properties) and prolong the circulation of nanoparticles in the complicated in vivo environment.

Herein, novel amphiphilic Y-shaped copolymers, a common type of star-shaped copolymers, composed of P(LA-co-GA) and PEG, were designed and synthesized. In detail, a series of amphiphilic Y-shaped monomethoxy poly(ethylene glycol)-poly(L-lactide-co-glycolide) ${ }_{2}$ (mPEG$\mathrm{P}(\mathrm{LA}-\mathrm{co}-\mathrm{GA})_{2}$ ) copolymers were synthesized by ROP of L-lactide and glycolide, with mPEG-(OH) ${ }_{2}$ as macroinitiator and stannous octoate $\left(\mathrm{Sn}(\mathrm{Oct})_{2}\right)$ as catalyst. The obtained copolymers formed into micellar/vesicular nanoparticles by altering the length of the hydrophobic P(LA-co-GA) block in phosphate buffer (PB) at $\mathrm{pH}$ 7.4. DOX, a model anticancer drug, could be loaded into the cores of nanoparticles, yielding micellar/vesicular nanomedicines. In vitro DOX release from the nanomedicines in $\mathrm{PB}$ was found to be accelerated by the decrease of polyester content or in tumor tissular and intracellular acidic conditions. The biocompatibilities and hemocompatibilities of the copolymers, and the cellular proliferation inhibition of the nanomedicines were also investigated. These properties indicated that the amphiphilic Y-shaped copolymers are promising materials for designing and fabricating DOX-based nanomedicines for efficient cancer treatment.

\section{Materials and methods Materials}

Monomethoxy poly(ethylene glycol) $\left(\mathrm{mPEG}_{113}, M_{\mathrm{n}}=5000\right)$ was purchased from Sigma-Aldrich (St Louis, MO) without further purification. Dowex 50W-X2 ion exchange resin was obtained from Sigma-Aldrich and used after a simple methanol rinse. Stannous octoate $\left(\operatorname{Sn}(\mathrm{Oct})_{2}\right)(>95 \%$, Sigma-Aldrich), 2,2-dimethoxypropane (DMP; Sinopharm Chemical Reagent Co, Ltd), 2,2-bis(hydroxymethyl) propionic acid (BHPA; Sinopharm Chemical Reagent Co, Ltd), and 4-dimethylaminopyridine (DMAP) (GL; Biochem Co, Ltd) were used as obtained. Acetonide-2,2bis(hydroxymethyl) propionic anhydride (ABHPA) was prepared from DMP and BHPA according to the procedure outlined in the literature. ${ }^{30}$ L-Lactide and glycolide were recrystallized with ethyl acetate before use. Doxorubicin hydrochloride (DOX.HCl) was purchased from Zhejiang Hisun Pharmaceutical Co, Ltd and used as obtained. Toluene was stored over calcium hydride $\left(\mathrm{CaH}_{2}\right)$ and purified by vacuum distillation. All the other reagents and solvents were purchased from Sinopharm Chemical Reagent Co, Ltd and used without further purification.

\section{Synthesis of double hydroxyl functionalized mPEG (mPEG- $(\mathrm{OH})_{2}$ )}

mPEG-(OH $)_{2}$ was synthesized by esterification of $\mathrm{mPEG}$ with ABHPA, using DMAP as a catalyst and the subsequent deprotection of acetonide groups, as depicted in Figure 1. Briefly, mPEG (10 g, 2 mmol), ABHPA (2.05 g, $6.1 \mathrm{mmol}$ ), and DMAP (0.23 g, $1.82 \mathrm{mmol})$ were dissolved in $60 \mathrm{~mL}$ of a methylene chloride $\left(\mathrm{CH}_{2} \mathrm{Cl}_{2}\right) /$ pyridine $(9 / 1, \mathrm{v} / \mathrm{v})$ mixed solvent and stirred overnight at $25^{\circ} \mathrm{C}$. Then, $10 \mathrm{~mL}$ of methanol was added to the mixture and allowed to stir for 5 hours to quench the excess ABHPA. Finally, the product was precipitated in excessive diethyl ether. The obtained product was further washed, twice, with diethyl ether, and dried under vacuum at room temperature for 24 hours (yield: 97\%). 


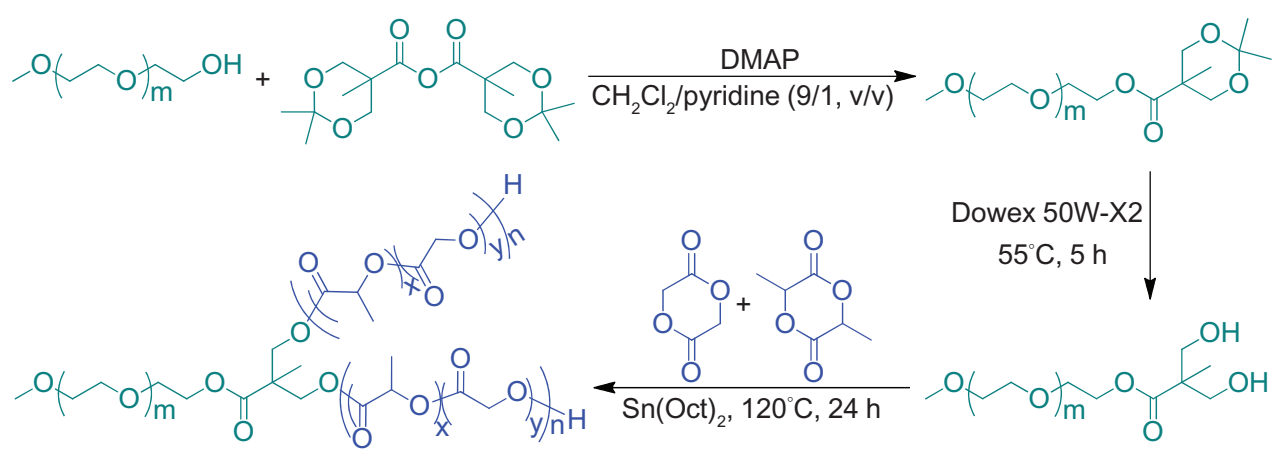

Figure I Synthesis pathway of $Y$-shaped mPEG-P(LA-co-GA) ${ }_{2}$ copolymers.

Abbreviations: DMAP, 4-dimethylaminopyridine; $\mathrm{Sn}(\mathrm{Oct})_{2}$, stannous octoate; mPEG, monomethoxy poly(ethylene glycol); $\mathrm{P}(\mathrm{LA}-\mathrm{co}-\mathrm{GA})$, poly(L-lactide-co-glycolide).

${ }^{1} \mathrm{H}$ NMR (400 MHz, $\left.\mathrm{CDCl}_{3}, \mathrm{ppm}\right): 1.22$ (s, 3H, - $\left.\mathrm{CH}_{3}\right), 1.43$ $\left(\mathrm{s}, 6 \mathrm{H},-\mathrm{OC}\left(\left(\mathrm{CH}_{3}\right)_{2}\right) \mathrm{O}-\right), 3.39\left(\mathrm{~s}, 3 \mathrm{H},-\mathrm{OCH}_{3}\right), 3.40-3.91$ $\left(4 \mathrm{H},-\mathrm{OCH}_{2} \mathrm{CH}_{2} \mathrm{O}-\right), 4.19-4.30\left(\mathrm{~m}, 6 \mathrm{H},-\mathrm{CH}_{2} \mathrm{CH}_{2} \mathrm{OC}(\mathrm{O})-\right.$, $\left.-\mathrm{OCH}_{2} \mathrm{C}(\mathrm{C}(\mathrm{O}))\left(\mathrm{CH}_{3}\right) \mathrm{CH}_{2} \mathrm{O}-\right)$. Subsequently, the resultant product was dissolved in $150 \mathrm{~mL}$ of methanol, and then $3.0 \mathrm{~g}$ of Dowex $50 \mathrm{~W}-\mathrm{X} 2$ was added to the solution. After stirring for 5 hours at $55^{\circ} \mathrm{C}$, the Dowex $50 \mathrm{~W}$-X2 was filtered out, and the remaining filtrate was precipitated in diethyl ether. The precipitate was collected and dried under vacuum to constant weight, at room temperature. The yield was approximately 98\%. ${ }^{1} \mathrm{H}$ NMR (400 MHz, $\mathrm{CDCl}_{3}, \mathrm{ppm}$ ): 1.12 (s, 3H, - $\mathrm{CH}_{3}$ ), $3.38\left(\mathrm{~s}, 3 \mathrm{H},-\mathrm{OCH}_{3}\right), 3.40-3.92\left(4 \mathrm{H},-\mathrm{OCH}_{2} \mathrm{CH}_{2} \mathrm{O}-\right), 4.35$ ( $\mathrm{t}, 2 \mathrm{H},-\mathrm{CH}_{2} \mathrm{CH}_{2} \mathrm{OC}(\mathrm{O})-$ ).

\section{Synthesis of amphiphilic Y-shaped copolymers (mPEG-P(LA-co-GA) $)_{2}$}

Various mPEG-P(LA-co-GA) ${ }_{2}$ copolymers with different compositions (various LA/GA molar ratios) were easily prepared by the ROP of L-lactide and glycolide in the presence of mPEG- $(\mathrm{OH})_{2}$ as macroinitiator and $\mathrm{Sn}(\mathrm{Oct})_{2}$ as catalyst (Figure 1). In brief, mPEG- $(\mathrm{OH})_{2}$ was dissolved in freshly distilled toluene and azeotropically distilled at $120^{\circ} \mathrm{C}$ to remove micro-amounts of water. Then, L-lactide, glycolide, $\mathrm{Sn}(\mathrm{Oct})_{2}$, and additional toluene were added. The mixture was stirred for 24 hours at $120^{\circ} \mathrm{C}$ under nitrogen. The product was precipitated in diethyl ether. The precipitate was collected and dried under vacuum to constant weight at room temperature (yield: 80-85\%).

\section{Preparation of mPEG-P(LA-co-GA) nanoparticles}

mPEG-P(LA-co-GA) 2 (10.0 mg) was dissolved in $2 \mathrm{~mL}$ of tetrahydrofuran (THF), and then stirred at room temperature for 2 hours. Subsequently, $1 \mathrm{~mL}$ of deionized water was added dropwise to the solution, under gentle stirring.
After stirring for 2 hours at room temperature, the THF was removed by dialysis against deionized water for 24 hours to obtain the solution of nanoparticles.

\section{Characterization}

Proton nuclear magnetic resonance $\left({ }^{1} \mathrm{H}\right.$ NMR) spectra were recorded on a Bruker AV 400 NMR spectrometer in chloroform- $d\left(\mathrm{CDCl}_{3}\right)$. Fourier transform infrared (FT-IR) spectra were recorded on a Bio-Rad Win-IR instrument using the potassium bromide $(\mathrm{KBr})$ method. Number- and weight-average molecular weights $\left(M_{\mathrm{n}}, M_{\mathrm{w}}\right)$ and molecular weight distributions (polydispersity index, PDI $\left.=M_{\mathrm{w}} / M_{\mathrm{n}}\right)$ were determined by gel permeation chromatography (GPC), using a series of linear Styragel columns $\left(\mathrm{HT}_{3}\right.$ and $\mathrm{HT}_{4}$ ) and a Waters 515 HPLC pump, with an OPTILAB DSP Interferometric Refractometer (Wyatt Technology) as detector. The eluent was chloroform at a flow rate of $1.0 \mathrm{~mL} \mathrm{~min}^{-1}$ at $40^{\circ} \mathrm{C}$. The monodispersed polystyrene standards with a molecular weight range from 1,310 to 55,100 were purchased from Waters Co, Ltd, and used to generate the calibration curve. Dynamic laser scattering (DLS) measurements were carried out on a WyattQELS instrument with a vertically polarized He-Ne laser (DAWN EOS, Wyatt Technology). The scattering angle was fixed at $90^{\circ}$. The morphologies of the mPEG-P(LA-co-GA) ${ }_{2}$ nanoparticles were confirmed by using transmission electron microscopy (TEM) measurement on a JEOL JEM-1011 transmission electron microscope with an accelerating voltage of $100 \mathrm{KV}$. A drop of the nanoparticle solution $\left(0.5 \mathrm{~g} \mathrm{~L}^{-1}\right)$ was deposited onto a 230-mesh copper grid coated with carbon, and laid to dry in air at $25^{\circ} \mathrm{C}$ before measuring. The critical aggregation concentration (CAC) was determined by fluorescence spectroscopy, using pyrene as the fluorescence probe on a PTI Fluorescence Master System with Felix 4.1.0 software $\left(\lambda_{\text {em }}=390 \mathrm{~nm}\right)$. The CAC was obtained from the intersection of the tangent to the horizontal line of 
$I_{336.5} / I_{334}$, with relative constant values and the diagonal line, with rapidly increased $I_{336.5} / I_{334}$ ratio.

\section{Fabrication of nanomedicine and in vitro DOX release}

The nanomedicines were prepared by the solventdisplacement (nanoprecipitation) method (Figure 2). Briefly, mPEG-P(LA-co-GA) $2(50.0 \mathrm{mg}), \mathrm{DOX} \cdot \mathrm{HCl}$ $(10.0 \mathrm{mg})$, and triethylamine $(1.8 \mathrm{mg})$ were dissolved in $3.0 \mathrm{~mL}$ of THF and stirred at room temperature for 5 hours. Then, $1 \mathrm{~mL}$ of deionized water was added dropwise to this solution under stirring. The mixture was stirred at room temperature for 6 hours, and then the solution was dialyzed against deionized water for 24 hours, using a dialysis bag (MWCO $3500 \mathrm{Da}$ ), to eliminate THF and excess DOX. The solution was filtered and lyophilized to obtain the nanomedicine. The drug-loading content (DLC) and drugloading efficiency (DLE) of the nanomedicine were calculated by the following equations: DLC (wt \%) $=$ (amount of drug in nanomedicine/amount of nanomedicine) $\times 100$, DLE $(w t \%)=($ amount of drug in nanomedicine/total amount of feeding drug) $\times 100$.

In vitro DOX release behaviors from the nanomedicines were investigated in $\mathrm{PB}$ at $\mathrm{pH}$ 5.3, 6.8, and 7.4. The weighed freeze-dried nanomedicine was suspended in $2 \mathrm{~mL}$ of $\mathrm{PB}$ and introduced into a dialysis bag (MWCO $3500 \mathrm{Da})$. The release experiment was initiated by placing the end-sealed dialysis bag into $50 \mathrm{~mL}$ of $\mathrm{PB}$ at $37^{\circ} \mathrm{C}$, with continuous shaking, at $75 \mathrm{rpm}$. At given times, $2 \mathrm{~mL}$ of external release medium was taken out, and the volume withdrawn was replenished with an equal volume of fresh release medium. The amount of released drug was tested by UV-vis spectrophotometry at $480 \mathrm{~nm}$, using the standard curve method.

\section{Intracellular DOX release}

The intracellular release behaviors of the nanomedicines were monitored via confocal laser scanning microscopy (CLSM) against Henrietta Lack's (HeLa) cells (a human cervical carcinoma cell line). The cells were seeded in 6-well culture plates at $\sim 200,000$ cells in $2 \mathrm{~mL}$ of complete Dulbecco's modified Eagle's medium (DMEM) per well and cultured for 24 hours. Then, the culture medium was removed and nanomedicines were added at a final DOX concentration of $10 \mathrm{mg} \mathrm{L}^{-1}$ (in $2 \mathrm{~mL}$ of complete DMEM medium). Free DOX was used as control. The cells were incubated with nanomedicines or free DOX for 2 hours. Afterwards, the culture media were removed and the cells were washed four times with PB and fixed with $4 \%$ formaldehyde for 30 minutes at room temperature, and the cell nuclei were dyed with 4',6-diamidino2-phenylindole (DAPI, blue). CLSM images of the cells were obtained with a confocal microscope (Olympus FluoView 1000).

\section{Cytotoxicity assay}

The cytotoxicities of the nanoparticles and nanomedicines were analyzed using methyl thiazolyl tetrazolium (MTT) viability assays toward HeLa cells. The cells were seeded in 96-well culture plates at a density of 7000 cells per well in $200 \mu \mathrm{L}$ of DMEM containing $10 \%$ fetal bovine serum, supplemented with $50 \mathrm{U} \mathrm{mL}^{-1}$ penicillin and $50 \mathrm{U} \mathrm{mL}^{-1}$ streptomycin, and incubated at $37^{\circ} \mathrm{C}$ in $5 \% \mathrm{CO}_{2}$ atmosphere for 24 hours. Then, the culture medium was removed and nanoparticles $\left(0-100 \mathrm{~m} \mathrm{~L}^{-1}\right)$ or nanomedicines ( $\left.0-10 \mathrm{mg} \mathrm{L}^{-1} \mathrm{DOX}\right)$ were added to $200 \mu \mathrm{L}$ of complete DMEM medium. The cells were subjected to MTT assay after being incubated for three time intervals (24, 48 , and 72 hours), at $37^{\circ} \mathrm{C}$, in $5 \% \mathrm{CO}_{2}$ atmosphere. The absorbance of the medium was measured at $490 \mathrm{~nm}$ on a Bio-Rad 680 microplate reader. Cell viability was calculated based on the following equation: Cell viability (\%) $=\left(A_{\text {sample }} / A_{\text {control }}\right) \times 100$, where $A_{\text {sample }}$ and $A_{\text {control }}$ are denoted as absorbencies of the sample and control wells, respectively.

\section{Hemolysis assay}

Hemolytic activities of the nanoparticles and nanomedicines were assessed, using spectrophotometry, by monitoring the release of hemoglobin from rabbit blood. Potassium oxalatestabilized rabbit blood samples were freshly obtained from the

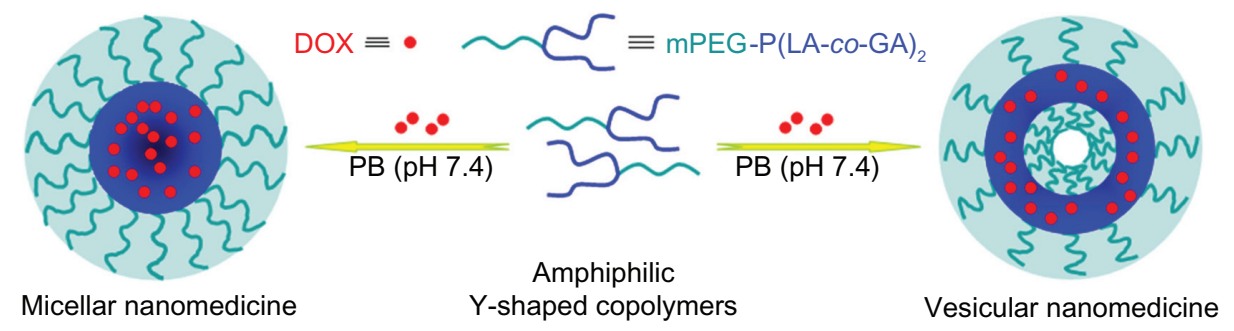

Figure 2 Schematic illustration of preparation of micellar/vesicular nanomedicines based on DOX and amphiphilic Y-shaped copolymers. Abbreviations: DOX, doxorubicin; mPEG, monomethoxy poly(ethylene glycol); P(LA-co-GA), poly(L-lactide-co-glycolide); PB, phosphate buffer. 
Experimental Animal Center of Jilin University. First, $5 \mathrm{~mL}$ of blood sample was diluted in $30 \mathrm{~mL}$ of physiological saline; then, red blood cells (RBCs) were isolated from the serum by centrifugation at $1200 \mathrm{rpm}$ for 10 minutes. The supernatant was carefully removed. The RBCs were further washed five times with $30 \mathrm{~mL}$ of physiological saline. The purified blood was diluted in $15 \mathrm{~mL}$ of physiological saline. Then, $0.4 \mathrm{~mL}$ of diluted RBC suspension was added to $0.4 \mathrm{~mL}$ solutions of nanoparticles and nanomedicines, at systematically varied concentrations, and mixed by vortexing. Physiological saline (-) and Triton X-100 $\left(10 \mathrm{~g} \mathrm{~L}^{-1}\right)(+)$ were used as negative and positive controls, respectively. All the sample tubes were kept under static conditions at $37^{\circ} \mathrm{C}$ for 1 hour. Finally, the mixtures were centrifuged at $3000 \mathrm{rpm}$ for 10 minutes, and $100 \mu \mathrm{L}$ of supernatants from all the samples were transferred to a 96-well plate. The absorbance values of the supernatants at $540 \mathrm{~nm}$ were determined by a Bio-Rad 680 microplate reader. The hemolysis ratio (HR) of the RBCs was calculated using the following formula: hemolysis $(\%)=\left(A_{\text {sample }}-A_{\text {negative control }}\right) /\left(A_{\text {positive control }}-A_{\text {negative control }}\right) \times$ 100, where $A_{\text {sample }}, A_{\text {negitive control }}$ and $A_{\text {positive control }}$ are denoted as absorbencies of the sample, and negative and positive controls, respectively. All hemolysis experiments were carried out in triplicate.

\section{Statistical analysis}

All the experiments were repeated at least three times. Data were expressed as mean \pm standard deviation (SD). All results were analyzed with a two-tailed Student's $t$-test. A value of $P<0.05$ was considered statistically significant.

\section{Results and discussion Synthesis and characterization of mPEG-P(LA-co-GA)}

The aliphatic polyesters can be directly synthesized by ROP of lactone monomers, using covalent metal alkoxides or carboxylates (eg, aluminum isopropoxide and $\mathrm{Sn}(\mathrm{Oct})_{2}$ ) as catalysts. ${ }^{31,32}$ In this work, four types of amphiphilic mPEG$\mathrm{P}(\mathrm{LA}-\mathrm{co}-\mathrm{GA})_{2}$ copolymers, with different contents of P(LAco-GA), were synthesized by ROP of L-lactide and glycolide, with $\mathrm{mPEG}-(\mathrm{OH})_{2}$ as macroinitiator and $\mathrm{Sn}(\mathrm{Oct})_{2}$ as catalyst. As shown in Figure 1 and Table 1, the polymerization was conducted in toluene at $120^{\circ} \mathrm{C}$, with $-\mathrm{OH} / \mathrm{LA} / \mathrm{GA}$ monomer feed molar ratios of 1/7/10,1/15/10,1/30/10, and 1/60/20. The chemical structures of mPEG-P(LA-co-GA), were confirmed by ${ }^{1} \mathrm{H}$ NMR and FT-IR spectra (Figure 3 ). The ${ }^{1} \mathrm{H}$ NMR spectra verified the successful synthesis of mPEG$\mathrm{P}(\mathrm{LA}-\mathrm{Co}-\mathrm{GA})_{2}$, and all signals were well assigned, as shown in Figure 3A. The degrees of polymerization (DP, Table 1) of two monomers (LA and GA) in the resultant mPEG-P(LAco-GA) $)_{2}$ were calculated by comparing the integrated area of peak at (a) 5.17 ppm attributed to methylene proton of the LA group and (b) $4.83 \mathrm{ppm}$ assigned to the methylene proton of the GA group, with the signal at (e) 3.65 ppm of methylene proton of mPEG. The molar compositions of the LA/GA monomers in the resultant copolymers were calculated to be 4/9, 12/9, 24/8, and 45/15. The result of FT-IR (Figure 3B) also demonstrated the generation of P(LA-co-GA) block, based on the increased strength of carbonyl absorption at $1759 \mathrm{~cm}^{-1}\left(v_{\mathbf{C}=\mathbf{O}}\right)$, attributed to the ester bond.

The successful synthesis of Y-shaped copolymers was further confirmed by the GPC analyses, as shown in Figure 4. The unimodal peaks with decreased retention time, corresponding to higher molecular weights, demonstrated the formation of Y-shaped copolymers. The PDI values of the copolymers were around 1.21-1.34. The relatively low molecular weight distribution may be explained by the living character of the ROP of the GA and LA monomers catalyzed by $\mathrm{Sn}(\mathrm{Oct})_{2}$. It should be noted that the $M_{\mathrm{n}}$ measured by GPC was relatively higher than that measured by ${ }^{1} \mathrm{H}$ NMR, due to the structural difference between the resultant copolymers and the monodispersed polystyrene standards that were used to generate the calibration curve in GPC analyses. ${ }^{12,33}$

\section{Self-assembly behavior of mPEG-P (LA-co-GA)}

Amphiphilic copolymers are an interesting type of materials that can self-assemble into various morphologies in selective solvents. In this study, Y-shaped mPEG-P(LA-co-GA)

Table I Characterizations of mPEGP-(LA-co-GA) ${ }_{2}$ copolymers

\begin{tabular}{|c|c|c|c|c|c|}
\hline Copolymers & Feed molar ratio $^{a}$ & Resultant molar ratio ${ }^{b}$ & $M_{n}\left(\mathrm{~g} \mathrm{~mol}^{-1}\right)^{c}$ & $M_{n}\left(\mathrm{~g} \mathrm{~mol}^{-1}\right)^{d}$ & PDI $^{\mathbf{d}}$ \\
\hline $\mathrm{mPEG}_{113}-\mathrm{P}\left(\mathrm{LA}_{4}-\mathrm{co}-\mathrm{GA}_{9}\right)_{2}$ & $1 / 7 / 10$ & $1 / 4 / 9$ & 6700 & 8600 & 1.21 \\
\hline $\mathrm{mPEG}_{113}-\mathrm{P}\left(\mathrm{LA}_{12}-\mathrm{CO}-\mathrm{GA}_{9}\right)_{2}$ & $1 / 15 / 10$ & $1 / 12 / 9$ & 7900 & 12000 & 1.22 \\
\hline $\mathrm{mPEG}_{113}-\mathrm{P}\left(\mathrm{LA}_{24}-\mathrm{CO}-\mathrm{GA}_{8}\right)_{2}$ & $1 / 30 / 10$ & $1 / 24 / 8$ & 9500 & 14000 & 1.28 \\
\hline $\mathrm{mPEG}_{113}-\mathrm{P}\left(\mathrm{LA}_{45}-\mathrm{CO}-\mathrm{GA}_{15}\right)_{2}$ & $1 / 60 / 20$ & $1 / 45 / 15$ & 13300 & 19600 & 1.34 \\
\hline
\end{tabular}

Notes: a ${ }^{2}$ eed molar ratio of -OH/LA/GA; 'Resultant molar ratio of -OH/LA/GA, and determined by 'H NMR; 'Determined by 'H NMR; 'Determined by GPC.

Abbreviations: mPEG, monomethoxy poly(ethylene glycol); P(LA-co-GA), poly(L-lactide-co-glycolide); $M_{n}$, number-average molecular weight; PDI, polydispersity index; LA, L-lactide; GA, glycolide; 'H NMR, proton nuclear magnetic resonance; GPC, gel permeation chromatography. 

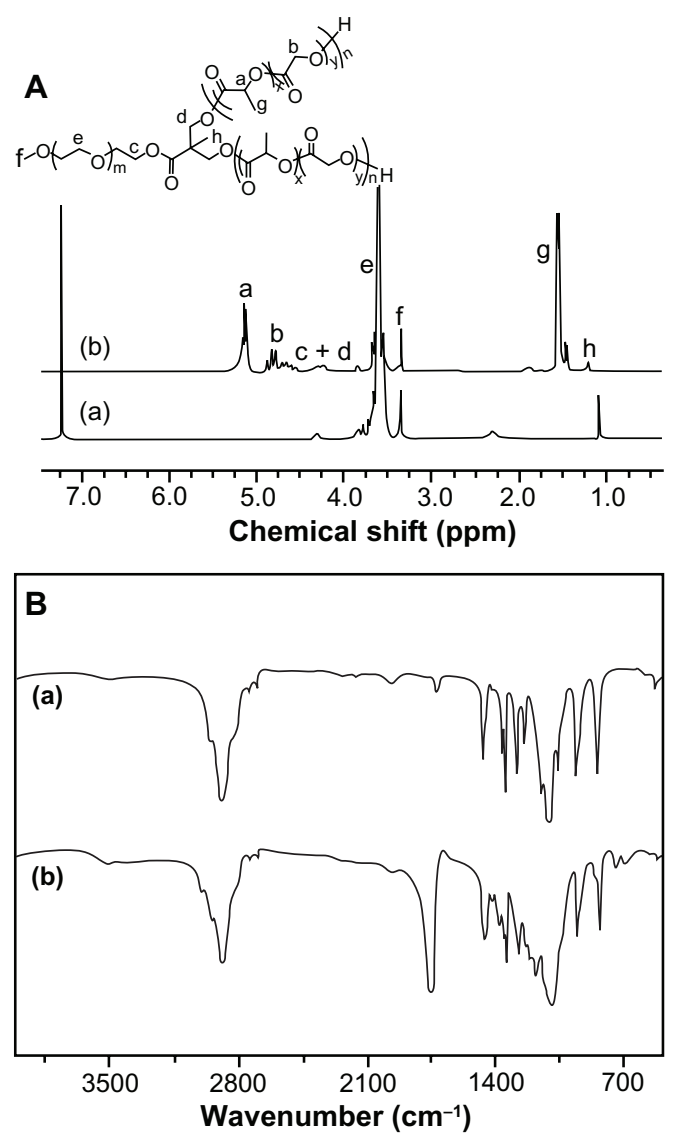

Figure 3 (A) 'H NMR and (B) FT-IR spectra of (a) $\mathrm{mPEG}_{113}-(\mathrm{OH})_{2}$ and (b) $\left.\mathrm{mPEG}_{113}-\mathrm{b}-\mathrm{P}\left(\mathrm{LA}_{12}-\mathrm{co}-\mathrm{GA}\right)_{9}\right)_{2}$.

Abbreviations: 'H NMR, proton nuclear magnetic resonance; FT-IR, Fourier transform infrared; mPEG, monomethoxy poly(ethylene glycol); P(LA-co-GA), poly(L-lactide-co-glycolide).

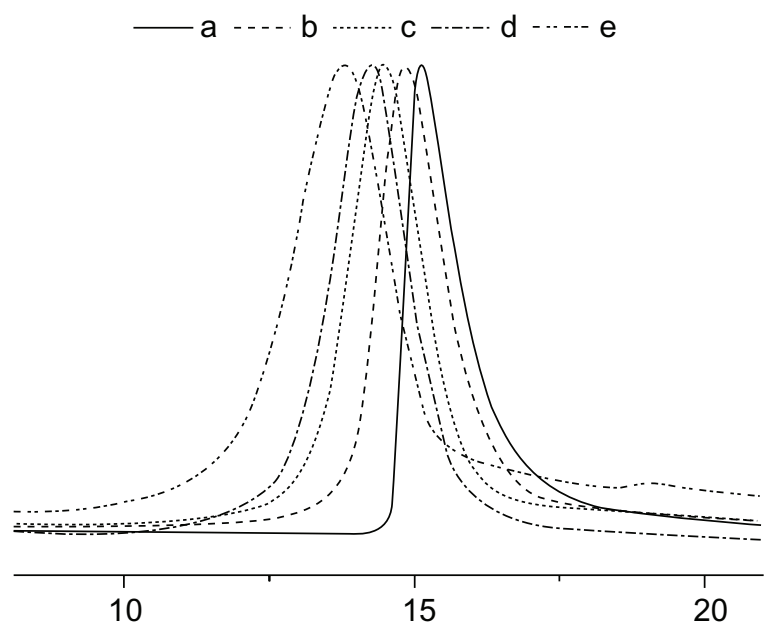

Elution time (min)

Figure $4 \mathrm{GPC}$ chromatograms of (a) mPEG-(OH) $)_{2}$, (b) mPEG-P(LA 4 -co-GA $)_{2}$,

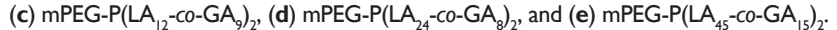
Abbreviations: GPC, gel permeation chromatography; mPEG, monomethoxy poly(ethylene glycol); $\mathrm{P}(\mathrm{LA}-\mathrm{co}-\mathrm{GA})$, poly(L-lactide-co-glycolide); $M_{n}$, number-average molecular weight; PDI, polydispersity index. copolymers were dissolved in THF, and the solution was mixed with water to induce microphase separation of the mPEG and P(LA-co-GA) blocks, followed by removing THF through dialysis. To demonstrate the formation of selfassembled aggregates, the widely reported pyrene-probebased fluorescence technique was used. ${ }^{34}$ The fluorescence excitation spectra of pyrene in $\mathrm{PB}$ solution of $\mathrm{mPEG}-\mathrm{P}\left(\mathrm{LA}_{12}{ }^{-}\right.$ co-(GA $)_{2}$ at different concentrations are shown in Figure 5A. It was obvious that fluorescence intensity increased as the copolymer concentration increased, due to the transfer of pyrene into a hydrophobic environment. A red shift of $(0,0)$ absorption band from 334.5 to $336 \mathrm{~nm}$ was observed when the copolymer concentration was increased from $6.10 \times 10^{-5}$ to $1.25 \times 10^{-1} \mathrm{~g} \mathrm{~L}^{-1}$. This red shift resulted from the transfer of pyrene molecules from a water environment to the hydrophobic core, and thus provided information on the location of the pyrene probe in the system, in fact, indicating the formation of aggregations. ${ }^{13}$ The critical
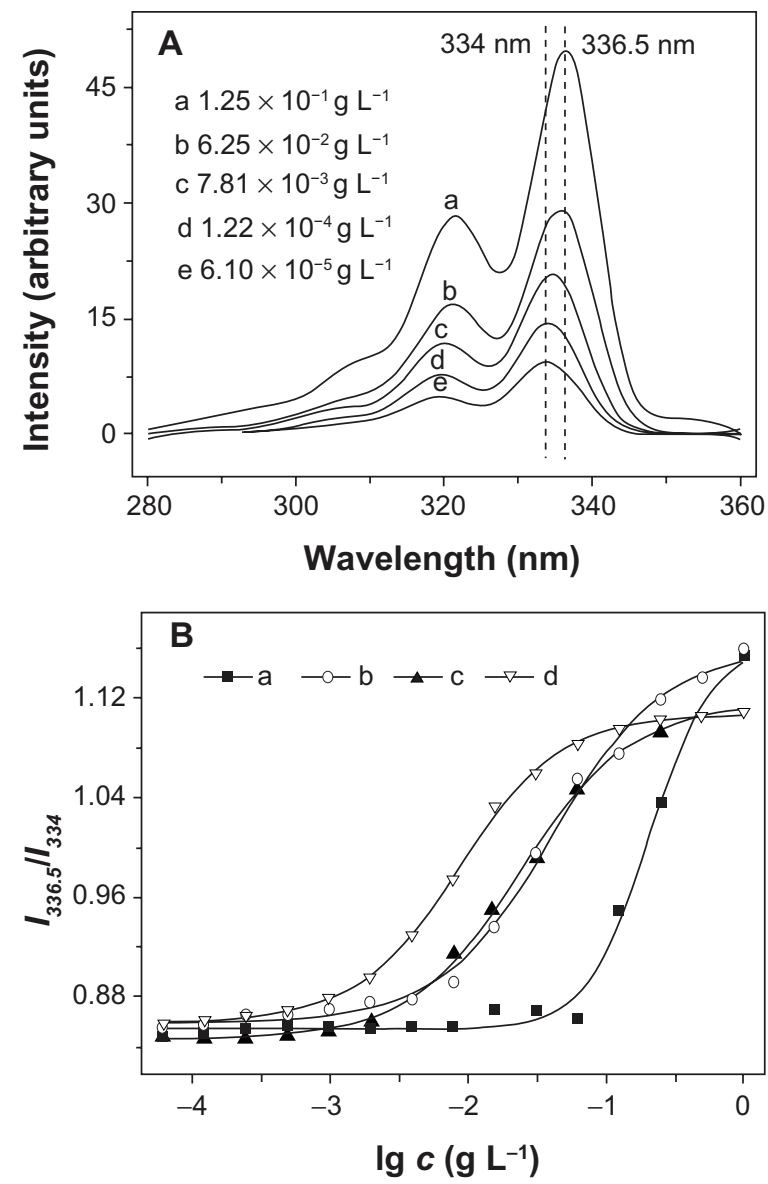

Figure 5 (A) Excitation spectra of pyrene in aqueous solution of mPEG-P(LA 12 -co$\left.\mathrm{GA}_{9}\right)_{2}$ at different concentrations $\left(\lambda_{\text {em }}=390 \mathrm{~nm}\right)$; (B) the intensity ratio $\left(I_{336.5} / I_{334}\right)$ as a function of concentration of (a) mPEG-P(LA $\left.{ }_{4}-\mathrm{co}_{-}-\mathrm{GA}_{9}\right)_{2}$, (b) mPEG-P( $\left(\mathrm{LA}_{12}-\mathrm{co}-\mathrm{GA}_{9}\right)_{2}$, (c) $\mathrm{mPEG}-\mathrm{P}\left(\mathrm{LA}_{24}-\mathrm{Co}-\mathrm{GA}_{8}\right)_{2}$, and (d) mPEG-P(LA $\left.\mathrm{LA}_{45}-\mathrm{Co}-\mathrm{GA}_{15}\right)_{2}$.

Abbreviations: mPEG, monomethoxy poly(ethylene glycol); P(LA-co-GA), poly(L-lactide-co-glycolide). 
aggregation concentration (CAC) was obtained from the plot of the fluorescence intensity ratio of $I_{336.5} / I_{334}$ versus $1 \mathrm{~g}$ $c$ of Y-shaped copolymers. The CAC values of copolymers decreased from $(6.53 \pm 0.1) \times 10^{-2}$ to $(1.52 \pm 0.1) \times 10^{-3} \mathrm{~g} \mathrm{~L}^{-1}$, with an increase in length of P(LA-co-GA) (Table 2). This was because the increase in hydrophobic P(LA-co-GA) length enhanced the probability of polyester backbone winding and interaction among the polyester chains.

As shown in Figure 2, the obtained amphiphilic mPEG$\mathrm{P}(\mathrm{LA}-\mathrm{co}-\mathrm{GA})_{2}$ copolymers self-assembled into micellar or vesicular nanoparticles in $\mathrm{PB}$ at $\mathrm{pH} 7.4$, depending on the length of hydrophobic P(LA-co-GA) moiety. The typical TEM micrographs of mPEG-P( $\left(\mathrm{LA}_{12}-\mathrm{Co}-\mathrm{GA}_{9}\right)_{2}$ micelles and mPEG-P( $\left(\mathrm{LA}_{24}-\mathrm{co}-\mathrm{GA}_{8}\right)_{2}$ vesicles in $\mathrm{PB}$ at $\mathrm{pH} 7.4,25^{\circ} \mathrm{C}$, are shown in Figure $6 \mathrm{~A}$ and $\mathrm{C}$, respectively. The morphologies and homogeneous sizes of the nanoparticles were observed by TEM. In addition, nanoparticle sizes were quantitatively determined by DLS in $\mathrm{PB}$ at $\mathrm{pH} 7.4,25^{\circ} \mathrm{C}$, and they are shown in Figure $6 \mathrm{~B}$ and $\mathrm{D}$, as well as Table 2. The hydrodynamic radii $\left(R_{\mathrm{h}}\right)$ values of the nanoparticles decreased from $88 \pm 2.5$ to $32 \pm 3.2 \mathrm{~nm}$ as the length of $\mathrm{P}(\mathrm{LA}-\mathrm{co}-\mathrm{GA})$ increased, except for $\mathrm{mPEG}_{113}-b-\mathrm{P}\left(\mathrm{LA}_{24}-c o-\mathrm{GA}_{8}\right)_{2}$, with an abnormal $R_{\mathrm{h}}$ of $144 \pm 1.4 \mathrm{~nm}$, attributed to its vesicular morphology.

\section{In vitro DOX loading and release}

DOX, an anthracycline anticancer drug, is one of the most common chemotherapeutic agents, known to have serious side effects, such as myelosuppression and cardiotoxicity. Formulation of DOX with nanocarriers through physical loading or chemical attachments into micellar/vesicular nanoparticles has been reported to improve the compatibility of DOX to normal tissues and enhance its therapeutic efficacy. ${ }^{35}$ In this study, DOX was chosen as a model anticancer drug and loaded into micellar and vesicular nanoparticles through a nanoprecipitation technique. Comparison of the drugloading abilities of the nanoparticles indicated that higher DLC and DLE were attributed to a longer hydrophobic P(LA-co-GA) block (Table 2). The values of DLC and DLE increased from $6.96 \pm 0.2$ to $10.34 \pm 0.2 \mathrm{wt} \%$ and from
$41.76 \pm 0.6$ to $62.04 \pm 0.4 \mathrm{wt} \%$, respectively, as the length of the P(LA-co-GA) segment increased.

First, the DOX release behaviors of three micellar nanomedicines were studied in $\mathrm{PB}$ at $\mathrm{pH}$ 5.3, 6.8, and 7.4, $37^{\circ} \mathrm{C}$, for 336 hours; the results are shown in Figure $7 \mathrm{~A}$. The copolymer composition was found to be correlated to the drug release kinetics at all test $\mathrm{pH}$ levels, and the release rate decreased with the increase of $\mathrm{P}(\mathrm{LA}-\mathrm{co}-\mathrm{GA})$ content, which led to more compact nanomedicine core, thus decreasing the DOX release rate. Moreover, the in vitro DOX release behaviors of all the micellar/vesicular nanomedicines were $\mathrm{pH}$-dependent. The release rate order was pH $5.3>$ pH $6.8>$ pH 7.4 (Figure 7), which corresponded to the $\mathrm{pHs}$ of late endosomes, tumor tissue, and the circulatory system, respectively. ${ }^{36}$ The accelerated DOX release at acidic $\mathrm{pH}$ can be attributed to the acid hydrolysis of ester bonds and the improvement of DOX solubility. ${ }^{37}$ In addition, it needs to be pointed out that all the nanomedicines displayed a relatively severe burst release in the current work, due to the weak interaction between P(LA-co-GA) and DOX. Fortunately, the burst drug release from the nanomedicines may be overcome by conjugating the drug molecules into nanoparticles through an acid-labile bond. ${ }^{38}$

It was more important to reveal DOX release from nanomedicines in living cells. The cellular uptake and intracellular release behaviors of the nanomedicines toward the HeLa cells were evaluated by CLSM to determine whether the DOX released effectively in the intracellular environment. The HeLa cells were incubated with micellar and vesicular nanomedicines, as well as free DOX (10 $\left.\mathrm{mg} \mathrm{L}^{-1} \mathrm{DOX}\right)$, for 2 hours. As shown in Figure 8, the strength of the intracellular DOX fluorescence in the HeLa cells, observed after 2 hours incubation, was nearly the same in the nanomedicines and free DOX. Moreover, the strength of the intracellular DOX fluorescence decreased as the P(LA-co-GA) content increased, which was concordant with extracellular release behavior. It has been reported that the incorporation of DOX into the hydrophobic cores of nanoparticles decreases the DOX fluorescence intensity compared with free DOX at the same concentration, due to

Table 2 Properties of mPEG-P(LA-co-GA) ${ }_{2}$ nanoparticles

\begin{tabular}{|c|c|c|c|c|c|c|c|}
\hline \multirow[t]{2}{*}{ Copolymers } & \multirow[t]{2}{*}{$\operatorname{CAC}\left(10^{-3} \mathrm{~g} \mathrm{~L}^{-1}\right)$} & \multirow[t]{2}{*}{$R_{\mathrm{h}}(\mathrm{nm})$} & \multirow[t]{2}{*}{ DLC (wt \%) } & \multirow[t]{2}{*}{ DLE (wt \%) } & \multicolumn{3}{|c|}{$I C_{50}\left(10^{-3} \mathrm{~g} \mathrm{~L}^{-1}\right)$} \\
\hline & & & & & $24 \mathrm{~h}$ & $48 h$ & $72 \mathrm{~h}$ \\
\hline $\mathrm{mPEG}_{113}-\mathrm{P}\left(\mathrm{LA}_{4}-\mathrm{co}-\mathrm{GA}_{9}\right)_{2}$ & $65.3 \pm 1.0$ & $88 \pm 2.5$ & $6.96 \pm 0.2$ & $41.76 \pm 0.6$ & 3.74 & 2.02 & 1.79 \\
\hline $\mathrm{mPEG}_{113}-\mathrm{P}\left(\mathrm{LA}_{12}-\mathrm{co}-\mathrm{GA}_{9}\right)_{2}$ & $5.68 \pm 0.2$ & $78 \pm 2.1$ & $7.35 \pm 0.3$ & $44.10 \pm 0.7$ & 3.13 & 1.91 & 1.83 \\
\hline $\mathrm{mPEG}_{113}-\mathrm{P}\left(\mathrm{LA}_{24}-\mathrm{co}-\mathrm{GA}_{8}\right)_{2}$ & $3.24 \pm 0.1$ & $144 \pm 1.4$ & $8.50 \pm 0.2$ & $51.00 \pm 0.5$ & 2.81 & 1.96 & 1.91 \\
\hline $\mathrm{mPEG}_{113}-\mathrm{P}\left(\mathrm{LA}_{45}-\mathrm{co}-\mathrm{GA}_{15}\right)_{2}$ & $1.52 \pm 0.1$ & $32 \pm 3.2$ & $10.34 \pm 0.2$ & $62.04 \pm 0.4$ & 4.08 & 1.94 & 1.73 \\
\hline
\end{tabular}

Abbreviations: mPEG, monomethoxy poly(ethylene glycol); P(LA-co-GA), poly(L-lactide-co-glycolide); CAC, critical aggregation concentration; $R_{\mathrm{h}}$, hydrodynamic radius; $\mathrm{DLC}$, drug loading content; DLE, drug loading efficiency; $\mathrm{IC}_{50}$, half maximal inhibitory concentration. 


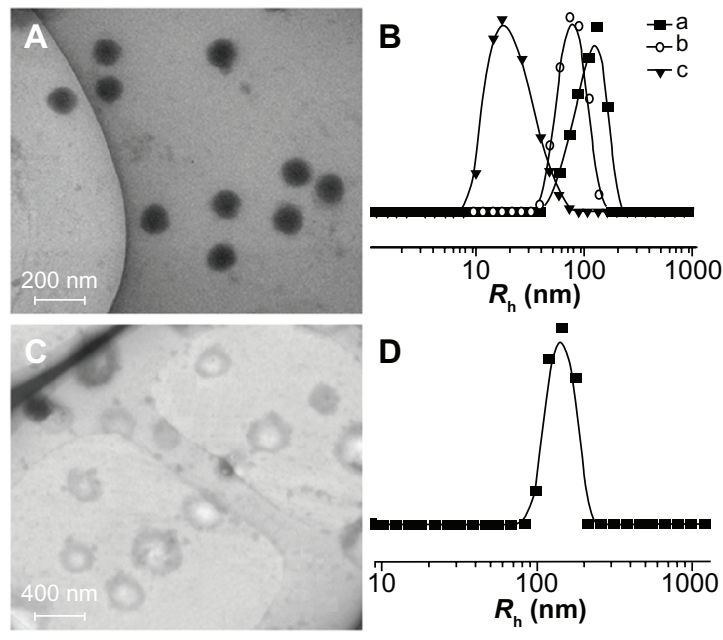

Figure 6 Typical TEM micrographs of $(\mathbf{A})$ mPEG-P(LA $\left(\mathrm{LA}_{12}-\mathrm{co}_{-}-\mathrm{GA}_{9}\right)_{2}$ and (C) mPEG-P $\left(\mathrm{LA}_{24}-\mathrm{co}-\mathrm{GA}_{8}\right)_{2}$, and $R_{\mathrm{h}}$ of (B) (a) mPEG-P(LA $\left.\mathrm{LA}_{4}-\mathrm{co}-\mathrm{GA}_{9}\right)_{2}$, (b) mPEG-P(LA 12 -co-GA $)_{2}$, and (c) mPEG-P(LA $\left.{ }_{45}-\mathrm{co}-\mathrm{GA}_{15}\right)_{2}$, and (D) mPEG-P(LA $\left.24-\mathrm{co}-\mathrm{GA}_{8}\right)_{2}$.

Abbreviations: TEM, transmission electron microscopy; $R_{\mathrm{h}}$, hydrodynamic radius; $\mathrm{mPEG}$, monomethoxy poly(ethylene glycol); $\mathrm{P}(\mathrm{LA}-\mathrm{co}-\mathrm{GA})$, poly(L-lactideco-glycolide).
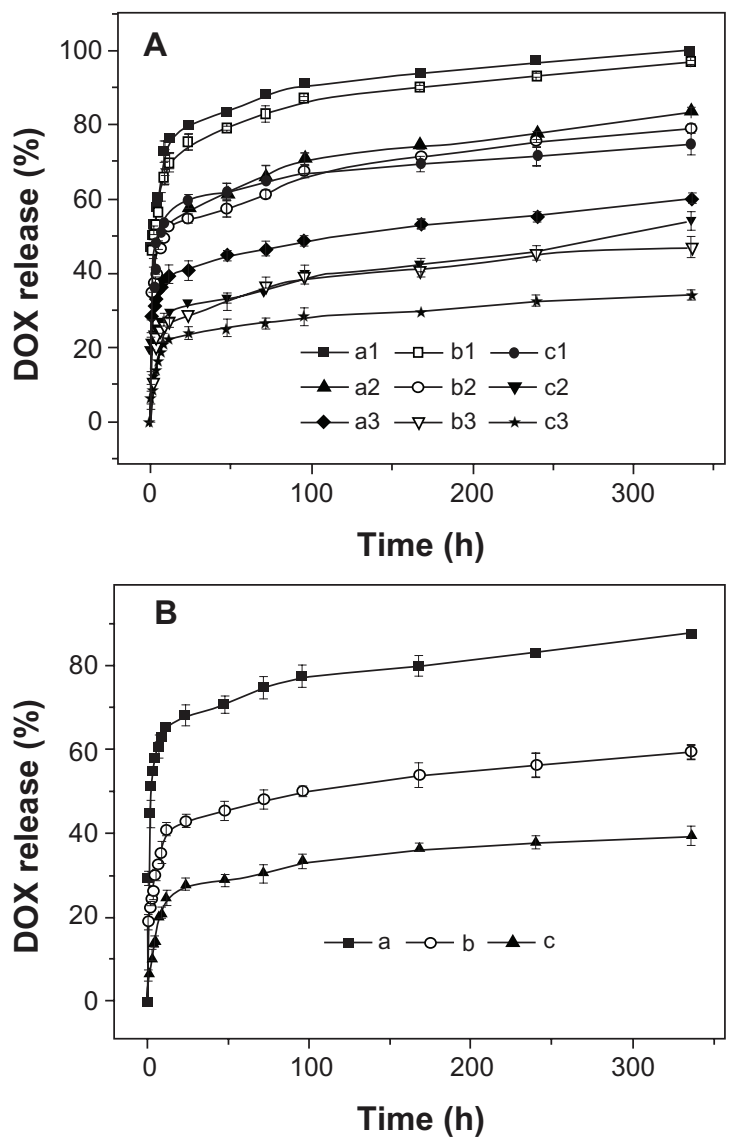

Figure 7 Release profiles of DOX from nanomedicines based on (A) (al, a2, a3) mPEG-P(LA - -Co-GA $\left._{9}\right)_{2}$, (bl, b2, b3) mPEG-P(LA 12 -co-GA $)_{2}$, and (cl, c2, c3) mPEG$\mathrm{P}\left(\mathrm{LA}_{45}-\mathrm{co}-\mathrm{GA}_{15}\right)_{2}$ micelles at $\mathrm{pH}(\mathbf{a l}, \mathbf{b l}, \mathbf{c l})$ 5.3, (a2, b2, c2) 6.8, and (a3, b3, c3) 7.4; (B) mPEG-P(LA $24^{-}$-co-GA $)_{2}$ vesicles at $\mathrm{PH}$ (a) 5.3 , (b) 6.8 , and (c) 7.4 in $\mathrm{PB}$ at $37^{\circ} \mathrm{C}$. Note: Data are presented as mean $\pm \operatorname{SD}(n=3)$.

Abbreviations: DOX, doxorubicin; mPEG, monomethoxy poly(ethylene glycol); P(LA-co-GA), poly(L-lactide-co-glycolide); PB, phosphate buffer; SD, standard deviation.
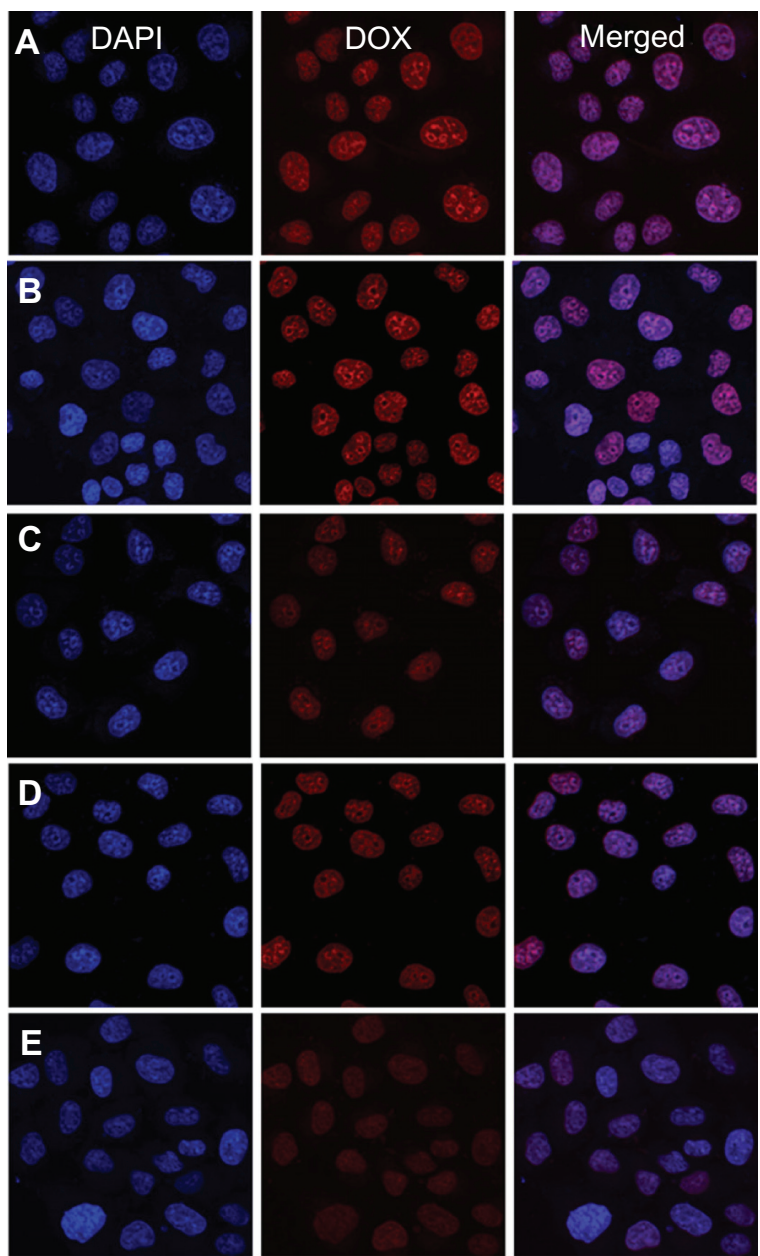

Figure 8 Representative CLSM images of HeLa cells incubated with free DOX and nanomedicines for 2 hours: incubated with $(\mathbf{A})$ free DOX and nanomedicines based on (B) mPEG-P(LA 4 -co-GA $)_{2}$ micelle, (C) mPEG-P(LA 12 -co-GA $)_{2}$ micelle, (D) mPEG-P(LA L $\left._{24}-\mathrm{co}-\mathrm{GA}_{8}\right)_{2}$ vesicle, and (E) mPEG-P(LA $\left.\mathrm{LA}_{45}-\mathrm{Co}-\mathrm{GA}_{15}\right)_{2}$ micelle. For each panel, the images from left to right show cell nuclei stained by DAPI (blue) and cellular DOX fluorescence (red), and overlays of the two images.

Abbreviations: DAPI, 4',6-diamidino-2-phenylindole; DOX, doxorubicin; CLSM, confocal laser scanning microscopy; HeLa, Henrietta Lacks; mPEG, monomethoxy poly(ethylene glycol); P(LA-co-GA), poly(L-lactide-co-glycolide).

the faster internalization of free DOX and the self-quenching effect of DOX in nanoparticles. ${ }^{8,35,39}$ Therefore, the enhanced fluorescence intensity in the HeLa cells incubated with micellar and vesicular nanomedicines should be the result of high endocytosis efficiency and improved intracellular DOX release from the nanomedicines.

\section{In vitro cytotoxicities of nanoparticles and nanomedicines}

MTT assays were used to estimate the in vitro cytotoxicities of nanoparticles and nanomedicines toward HeLa cells. As shown in Figure 9, the polyester nanoparticles showed no noticeable cytotoxicities up to $100 \mathrm{mg} \mathrm{L}^{-1}$, indicating their good biocompatibilities and displaying their potential as 


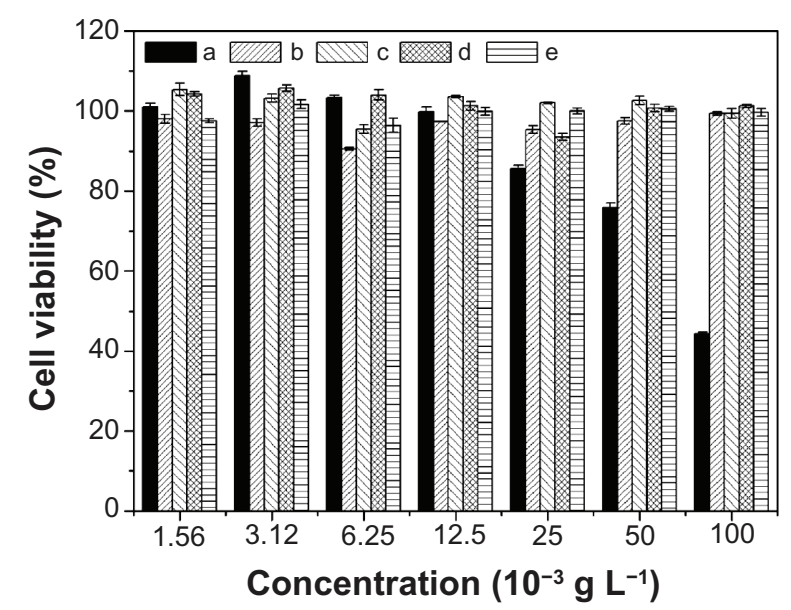

Figure 9 In vitro cytotoxicities of (a) PEI25K and nanoparticles from (b) mPEG-P(LA 4 -co-GA $)_{2}$, (c) mPEG-P(LA 12 -co-GA $)_{2}$, (d) mPEG-P(LA (d4 $\left._{2}-\mathrm{co}_{-}-\mathrm{GA}_{8}\right)_{2}$, and (e) mPEG-P(LA $\left.45-\mathrm{Co}-\mathrm{GA}_{15}\right)_{2}$ toward HeLa cells.

Note: Data are presented as mean $\pm \operatorname{SD}(n=6)$.

Abbreviations: PEl, polyethylenimine; mPEG, monomethoxy poly(ethylene glycol); $\mathrm{P}(\mathrm{LA}-\mathrm{co-GA})$, poly(L-lactide-co-glycolide); HeLa, Henrietta Lacks; $\mathrm{SD}$, standard deviation.

drug delivery vehicles. Furthermore, the cellular proliferation inhibitions of nanomedicines against HeLa cells were estimated after incubation for 24,48 , and 72 hours, using free DOX as control. As shown in Figure 10, the nanomedicines displayed an effective inhibitory effect on the proliferation of HeLa cells for all the test times. The half maximal inhibitory concentration $\left(\mathrm{IC}_{50}\right)$ values are listed in Table 2 . $\mathrm{The} \mathrm{IC}_{50}$ values of free DOX were $0.94,0.48$, and $0.44 \mathrm{mg} \mathrm{L}^{-1}$ at 24 , 48 , and 72 hours, respectively, which were lower than those of the nanomedicines with equivalent DOX. The somewhat lower toxicities of the nanomedicines compared to free DOX were probably due to the gradual release of DOX within the cells. The ability not only to minimize drug loss in blood circulation, but also to selectively accumulate in tumor tissue through EPR effects, may enhance its overall therapeutic efficacy in vivo relative to free DOX. In addition, with the prolongation of drug treatment time from 24 to 72 hours, the $\mathrm{IC}_{50}$ values of the nanomedicines decreased from $\sim 3$ to $\sim 1.8 \mathrm{mg} \mathrm{L}^{-1}$, quantificationally confirming that the nanomedicines were more effective after lengthy treatment.

Characterization of in vitro hemocompatibilities of nanoparticles and nanomedicines was important, as they were designed to be administered via intravenous injection for most drug delivery applications. The blood compatibilities of the micellar/vesicular nanoparticles and nanomedicines were assessed by hemolysis assay on rabbit RBCs. The HR represents the amount of $\mathrm{RBC}$ membrane destroyed by substances in contact with RBCs, as smaller HR values represent better blood compatibility of biomaterials. RBCs were
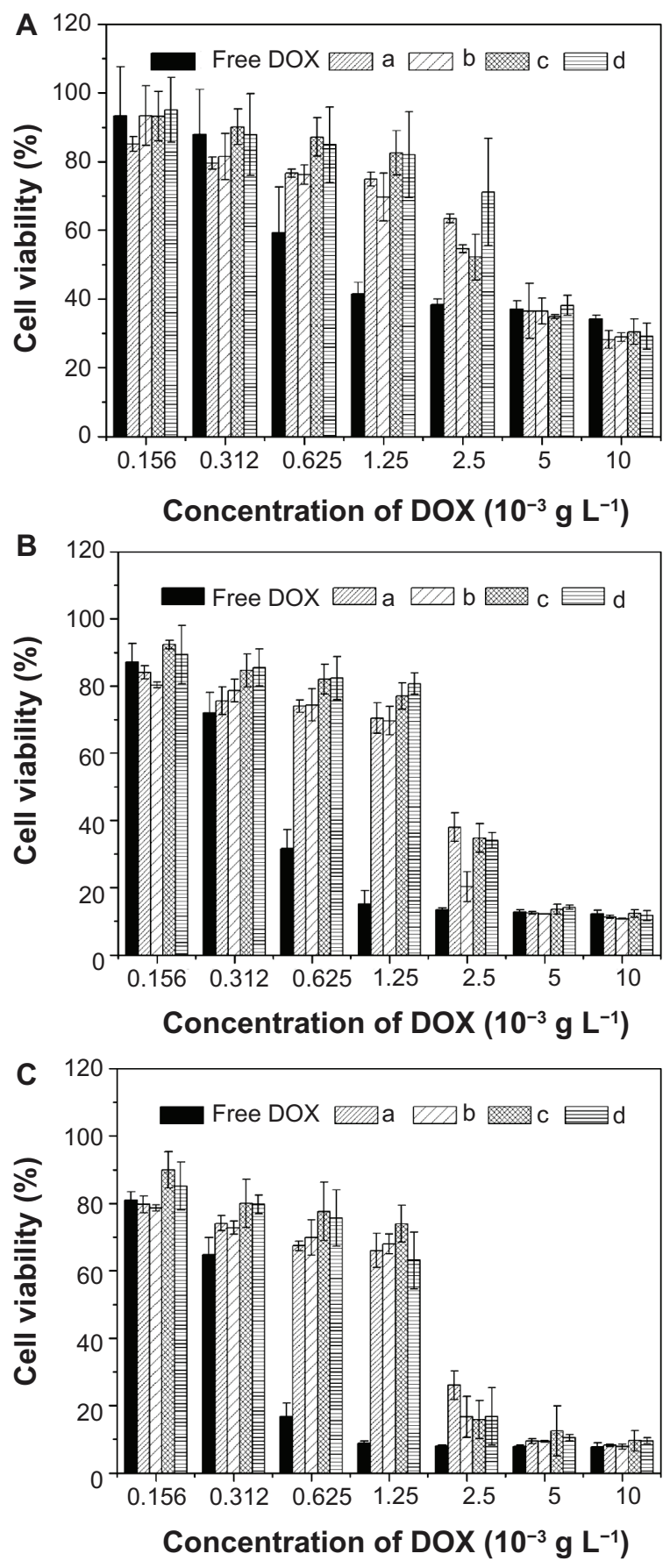

Figure 10 In vitro cytotoxicities of free DOX and nanomedicines based on (a) mPEG-P(LA 4 -co-GA $)_{2}$, (b) mPEG-P(LA 12 -co-GA $)_{2}$, (c) mPEG-P(LA $\left.{ }_{24}-\mathrm{co}_{-}-\mathrm{GA}_{8}\right)_{2}$, and (d) mPEG-P( $\left(\mathrm{LA}_{45}-\mathrm{CO}-\mathrm{GA}_{15}\right)_{2}$ at (A) 24, (B) 48, and (C) 72 hours toward HeLa cells. Note: Data are presented as mean \pm SD $(n=6)$.

Abbreviations: DOX, doxorubicin; mPEG, monomethoxy poly(ethylene glycol); P(LA-co-GA), poly(L-lactide-co-glycolide); HeLa, Henrietta Lacks; SD, standard deviation.

co-incubated with nanoparticles, nanomedicines, and free DOX at different concentrations for 1 hour, and then the HR values were determined by spectrophotometer (Figure 11). As shown in Figure 11A, none of the nanoparticles showed conspicuous hemolytic activities on RBC, even at the very 


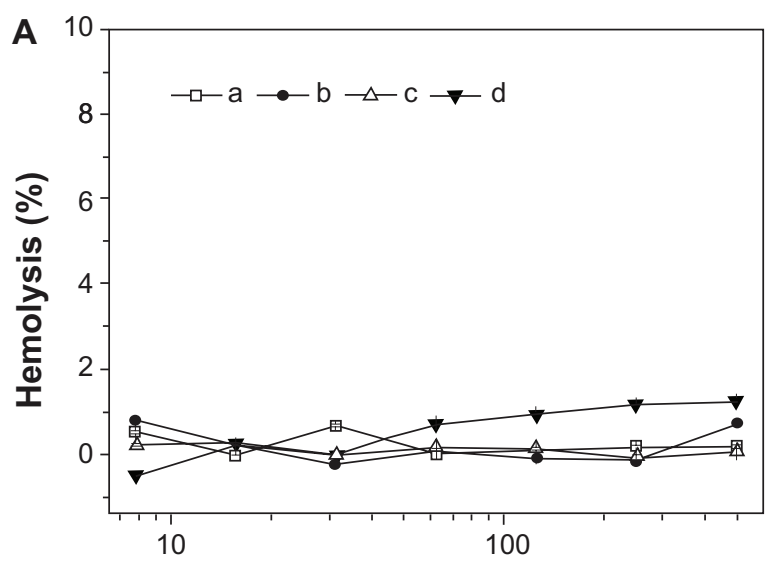

Concentration $\left(10^{-3} \mathrm{~g} \mathrm{~L}^{-1}\right)$

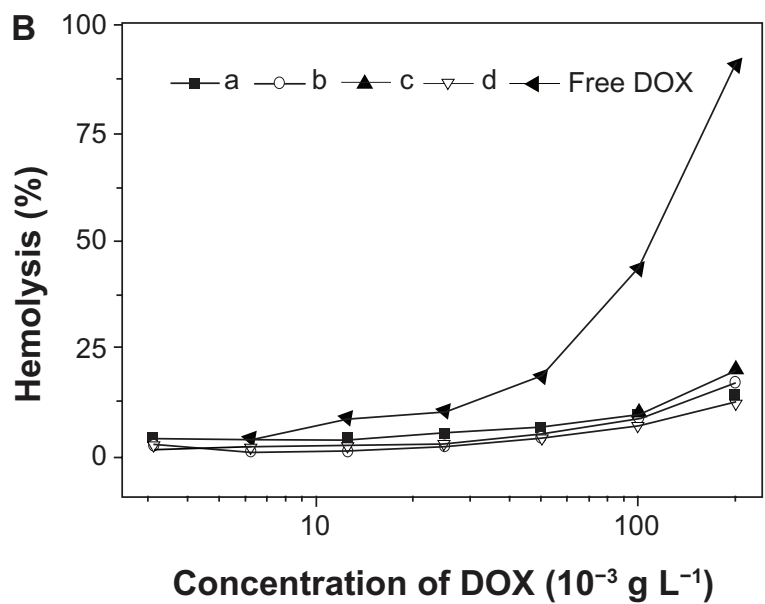

Figure II Percentage of RBC hemolysis incubated with (A) nanoparticles from

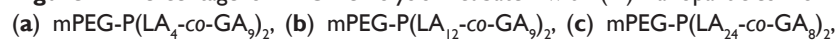
and (d) mPEG-P( $\left.\mathrm{LA}_{45}-\mathrm{Co}-\mathrm{GA}_{15}\right)_{2}$, and (B) (a-d) homologous nanomedicines and free DOX. Physiological saline (-) and Triton X-100 (10 $\left.\mathrm{g} \mathrm{L}^{-1}\right)(+)$ were used as negative and positive controls, respectively.

Note: Data are represented as mean $\pm S D(n=3)$.

Abbreviations: DOX, doxorubicin; RBC, red blood cell; mPEG, monomethoxy poly(ethylene glycol); P(LA-co-GA), poly(L-lactide-co-glycolide); SD, standard deviation.

high concentration of $\sim 0.5 \mathrm{~g} \mathrm{~L}^{-1}$, indicating great hemocompatible for potential biomedical application. In addition, the hemolytic activities of the nanomedicines were established with free DOX as control. As shown in Figure 11B, the nanomedicines were found to display less hemolysis activity toward RBCs compared with free DOX, indicating that the nanomedicines were hemocompatible, and thereby allowing the potential clinical applications.

\section{Conclusion}

Four novel amphiphilic Y-shaped mPEG-P(LA-co-GA) copolymers were prepared by alternating ROP of LA and GA monomers. The synthesized amphiphilic copolymers were substantiated to have exact chemical structure, controllable molecular weight, monodispersity, and amphiphilic properties. The copolymers formed into nanoscale micellar/ vesicular aggregations with hydrophobic polyester cores and mPEG shells in PB at $\mathrm{pH}$ 7.4. Micellar/vesicular nanomedicines were fabricated by loading DOX into the compact nanoparticles. The in vitro release could be accelerated by decreasing P(LA-co-GA) length and mimicking tumor tissular and intracellular acidic conditions $(\mathrm{pH} 6.8$ and 5.3, respectively). The intracellular DOX release could be improved by shortening the hydrophobic P(LA-co-GA) block, and the nanomedicines displayed effective proliferation inhibition against HeLa cells at 24, 48, and 72 hours. The nanoparticles were hemocompatible, and the presence of copolymers in the nanomedicines reduced the hemolysis ratio (HR) of DOX significantly. These properties suggest that the novel DOX and amphiphilic, Y-shaped copolymer-based anticancer nanomedicines are attractive candidates as tumor tissular and intracellular targeting drug delivery platforms in vivo, with enhanced stability during circulation and accelerated drug release at the target sites.

\section{Acknowledgments}

This research was financially supported by National Natural Science Foundation of China (Key Project 50733003, Projects 21104076, 51173184, 20904053, 20974109, 21004061, 21064010, and 50973108), Scientific Development Program of Jilin Province (Project 10ZDGG004), Knowledge Innovation Program of the Chinese Academy of Sciences (Grant No KJCX2-YW-H19), and Science and Technology Program of Changchun (Grant No 2010061).

\section{Disclosure}

The authors report no conflicts of interest in this work.

\section{References}

1. Kim SH, Tan JP, Nederberg F, et al. Hydrogen bonding-enhanced micelle assemblies for drug delivery. Biomaterials. 2010;31(31): 8063-8071.

2. Gu PF, Xu H, Sui BW, et al. Polymeric micelles based on poly(ethylene glycol) block poly(racemic amino acids) hybrid polypeptides: conformation-facilitated drug-loading behavior and potential application as effective anticancer drug carriers. Int J Nanomedicine. 2012;7:109-122.

3. Brinkhuis RP, Rutjes FPJT, van Hest JCM. Polymeric vesicles in biomedical applications. Polym Chem. 2011;2:1449-1462.

4. Ding J, Xiao C, He C, et al. Facile preparation of a cationic poly(amino acid) vesicle for potential drug and gene co-delivery. Nanotechnology. 2011;22(49):494012.

5. Tong R, Cheng J. Anticancer polymeric nanomedicines. Polym Rev. 2007; 47:345-381.

6. Dane KY, Nembrini C, Tomei AA, et al. Nano-sized drug-loaded micelles deliver payload to lymph node immune cells and prolong allograft survival. J Control Release. 2011;156(2):154-160.

7. Zhu WP, Wang Y, Zhang QJ, Shen Z. Amphiphilic PEG-grafted poly(ester-carbonate)s: synthesis and diverse nanostructures in water. J Polym Sci Part A: Polym Chem. 2011;49(22):4886-4893. 
8. Jeong YI, Kim DH, Chung CW, et al. Doxorubicin-incorporated polymeric micelles composed of dextran-b-poly(DL-lactide-coglycolide) copolymer. Int J Nanomedicine. 2011;6:1415-1427.

9. Cheng Y, He C, Xiao C, Ding J, Zhuang X, Chen X. Versatile synthesis of temperature-sensitive polypeptides by click grafting of oligo(ethylene glycol). Polym Chem. 2011;2:2627-2634.

10. Tanner P, Baumann P, Enea R, Onaca O, Palivan C, Meier W. Polymeric vesicles: from drug carriers to nanoreactors and artificial organelles. Acc Chem Res. 2011;44(10):1039-1049.

11. Maddikeri RR, Colak S, Gido SP, Tew GN. Zwitterionic polymersomes in an ionic liquid: room temperature TEM characterization. Biomacromolecules. 2011;12(10):3412-3417.

12. Ding JX, Xiao CS, Zhao L, et al. Poly(L-glutamic acid) grafted with oligo(2-(2-(2-methoxyethoxy)ethoxy)ethyl methacrylate): thermal phase transition, secondary structure, and self-assembly. J Polym Sci Part A: Polym Chem. 2011;49(12):2665-2676.

13. Cheng J, Ding JX, Wang YC, Wang J. Synthesis and characterization of star-shaped block copolymer of poly(epsilon-caprolactone) and poly(ethyl ethylene phosphate) as drug carrier. Polymer. 2008; 49(22):4784-4790.

14. Wang W, Ding J, Xiao C, et al. Synthesis of amphiphilic alternating polyesters with oligo(ethylene glycol) side chains and potential use for sustained release drug delivery. Biomacromolecules. 2011; 12(7):2466-2474.

15. Yousefpour P, Atyabi F, Farahani EV, Sakhtianchi R, Dinarvand R. Polyanionic carbohydrate doxorubicin-dextran nanocomplex as a delivery system for anticancer drugs: in vitro analysis and evaluations. Int J Nanomedicine. 2011;6:1487-1496.

16. Liu Q, Li RT, Qian HQ, et al. Gelatinase-stimuli strategy enhances the tumor delivery and therapeutic efficacy of docetaxel-loaded poly(ethylene glycol)-poly( $\varepsilon$-caprolactone) nanoparticles. Int $J$ Nanomedicine. 2012;7:281-295.

17. Layre A, Couvreur P, Chacun H, et al. Novel composite core-shell nanoparticles as busulfan carriers. J Control Release. 2006;111(3): 271-280.

18. Maglio G, Nicodemi F, Conte C, et al. Nanocapsules based on linear and Y-shaped 3-miktoarm star-block PEO-PCL copolymers as sustained delivery system for hydrophilic molecules. Biomacromolecules. 2011;12(12):4221-4229.

19. Liu J, Pang Y, Huang W, Zhu X, Zhou Y, Yan D. Self-assembly of phospholipid-analogous hyperbranched polymers nanomicelles for drug delivery. Biomaterials. 2010;31(6):1334-1341.

20. Ding M, He X, Wang Z, et al. Cellular uptake of polyurethane nanocarriers mediated by gemini quaternary ammonium. Biomaterials. 2011;32(35):9515-9524.

21. Kanaoka S, Sawamoto M, Higashimura T. Star-shaped polymers by living cationic polymerization. 4. Selective host-guest interaction of small molecules by amphiphilic star-shaped polymers of vinyl ethers. Macromolecules. 1992;25(24):6414-6418.

22. Nabid MR, Tabatabaei Rezaei SJ, Sedghi R, et al. Self-assembled micelles of well-defined pentaerythritol-centered amphiphilic A(4)B(8) star-block copolymers based on PCL and PEG for hydrophobic drug delivery. Polymer. 2011;52(13):2799-2809.

23. Ren T, Wang A, Yuan W, Li L, Feng Y. Synthesis, self-assembly, fluorescence, and thermosensitive properties of star-shaped amphiphilic copolymers with porphyrin core. J Polym Sci Part A: Polym Chem. 2011;49(10):2303-2313
24. Xu FJ, Yang WT. Polymer vectors via controlled/living radical polymerization for gene delivery. Prog Polym Sci. 2011;36(9): 1099-1131.

25. Maglio G, Nicodemi F, Conte C, et al. Nanocapsules based on linear and Y-shaped 3-miktoarm star-block PEO-PCL copolymers as sustained delivery system for hydrophilic molecules. Biomacromolecules. 2011;12(12):4221-4229.

26. Boyer C, Soeriyadi AH, Zetterlund PB, WhittakerMR. Synthesis of complex multiblock copolymers via a simple iterative $\mathrm{Cu}(0)$-mediated radical polymerization approach. Macromolecules. 2011;44(20): 8028-8033.

27. Kim SH, Tan JPK, Fukushima K, et al. Thermoresponsive nanostructured polycarbonate block copolymers as biodegradable therapeutic delivery carriers. Biomaterials. 2011;32(23):5505-5514.

28. El Habnouni S, Darcos V, Garric X, Lavigne J-P, Nottelet B, Coudane J. Mild methodology for the versatile chemical modification of polylactide surfaces: original combination of anionic and click chemistry for biomedical applications. Adv Funct Mater. 2011;21:3321-3330.

29. Preuss A, Hackbarth S, Wacker M, Knobloch T, Langer K, Roder B. Comprehensive in vitro investigations on biodegradable photosensitizer-nanoparticle delivery systems. J Control Release. 2010; 148(1): E117-E118

30. Magbitang T, Lee VY, Cha JN, et al. Oriented nanoporous lamellar organosilicates templated from topologically unsymmetrical dendritic-linear block copolymers. Angew Chem Int Ed Engl. 2005;44(46):7574-7580.

31. Pounder RJ, Dove AP. Towards poly(ester) nanoparticles: recent advances in the synthesis of functional poly(ester)s by ring-opening polymerization. Polym Chem. 2010;1:260-271.

32. Pang X, Zhuang XL, Tang ZH, Chen X. Polylactic acid (PLA): research, development and industrialization. Biotechnol J. 2010;5(11): $1125-1136$.

33. Ding J, Xiao C, Tang Z, Zhuang X, Chen X. Highly efficient "grafting from" an alpha-helical polypeptide backbone by atom transfer radical polymerization. Macromol Biosci. 2011;11(2):192-198.

34. Rodriguez-Hernandez J, Checot F, Gnanou Y, Lecommandoux S. Toward 'smart' nano-objects by self-assembly of block copolymers in solution. Prog Polym Sci. 2005;30(7):691-724.

35. Ding J, Shi F, Xiao C, et al. One-step preparation of reduction-responsive poly(ethylene glycol)- poly(amino acid)s nanogels as efficient intracellular drug delivery platforms. Polym Chem. 2011;2(12):2857-2864.

36. Zhou Z, Shen Y, Tang J, et al. Charge-reversal drug conjugate for targeted cancer cell nuclear drug delivery. Adv Funct Mater. 2009; 19(22):3580-3589.

37. Wang H, Zhao Y, Wu Y, et al. Enhanced anti-tumor efficacy by codelivery of doxorubicin and paclitaxel with amphiphilic methoxy PEG-PLGA copolymer nanoparticles. Biomaterials. 2011;32(32): 8281-8290.

38. Bae Y, Fukushima S, Harada A, Kataoka K. Design of environmentsensitive supramolecular assemblies for intracellular drug delivery: polymeric micelles that are responsive to intracellular $\mathrm{pH}$ change. Angew Chem Int Ed Engl. 2003;42(38):4640-4643.

39. Ding J, Xiao C, Yan L, et al. $\mathrm{pH}$ and dual redox responsive nanogel based on poly(1-glutamic acid) as potential intracellular drug carrier. J Control Release. 2011;152:E11-E13.
International Journal of Nanomedicine

\section{Publish your work in this journal}

The International Journal of Nanomedicine is an international, peerreviewed journal focusing on the application of nanotechnology in diagnostics, therapeutics, and drug delivery systems throughou the biomedical field. This journal is indexed on PubMed Central, MedLine, CAS, SciSearch ${ }^{\circledR}$, Current Contents ${ }^{\circledR} /$ Clinical Medicine,

\section{Dovepress}

Journal Citation Reports/Science Edition, EMBase, Scopus and the Elsevier Bibliographic databases. The manuscript management system is completely online and includes a very quick and fair peer-review system, which is all easy to use. Visit http://www.dovepress.com/ testimonials.php to read real quotes from published authors. 